\title{
Association between Depression and Renal Hyperfiltration in a General Chinese Population
}

\author{
Miao Lin ${ }^{a}$ Huibin Huang ${ }^{b}$ Jin Yao ${ }^{b}$ Jixing Liang ${ }^{b}$ Liantao Li $^{b}$ \\ Wei Lin ${ }^{b}$ Lixiang Lin ${ }^{b}$ Fuyuan Hong ${ }^{a}$ Jieli Luc Yufang $\mathrm{Bi}^{\mathrm{c}}$ \\ Weiqing Wang ${ }^{c}$ Junping Wen ${ }^{b}$ Gang Chen ${ }^{b}$ \\ ${ }^{a}$ Department of Nephrology, Fujian Shengli Clinical College, Fujian Medical University, \\ Fujian Provincial Hospital, Fuzhou, China; ${ }^{b}$ Department of Endocrinology, Fujian Shengli \\ Clinical College, Fujian Academy of Medical Sciences, Fujian Medical University, Fujian \\ Provincial Hospital, Fuzhou, China; ' ${ }^{2}$ epartment of Endocrinology, Ruijin Hospital, Shanghai \\ Jiaotong University School of Medicine, Shanghai, China
}

\section{Keywords}

Renal hyperfiltration - Depression - Depressive symptoms - Estimated glomerular filtration rate $\cdot$ Patient Health Questionnaire

\begin{abstract}
Background: Depression is prevalent in patients with all stages of CKD and is associated with adverse outcome. Abnormally elevated GFR, or hyperfiltration, may play a crucial role in the initiation and progression of CKD. However, the association between depression and hyperfiltration is not known. The aim of this study is to investigate the relationship between depression and hyperfiltration. Methods: This was an observational cross-sectional study. A total of 3,716 volunteers (1,303 males and 2,413 females) aged 40-75 years without CKD from a community in China were included for the study. Depressive symptoms and the presence of a minor or major depressive episode were assessed with the 9-item Patient Health Questionnaire (PHQ-9) and Diagnostic and Statistical Manual of Mental Disorders (4th edition)-based structured interview, respectively. Results: The mean age of the participants in the present study was $53.8 \pm 9.0$ years. 115 participants had clinically relevant depression, and 122 participants had a minor or major depressive episode. In a multivariable logistic regression analysis adjusted for potential confounders, the association between clinically relevant depression and renal hyperfiltration remained significant in men but not in women. As compared with men
\end{abstract}

Miao Lin, Huibin Huang, and Jin Yao contributed equally to the study.

Gang Chen, MD, PhD

Department of Endocrinology, Fujian Provincial Clinical College Fujian Provincial Hospital, Fujian Academy of Medical Sciences Fujian Medical University, No. 134 Dong Street, Fuzhou 350001 (China)

E-Mail chengangfj@163.com
Junping Wen, MD, PhD

Department of Endocrinology

Fujian Provincial Hospital, Fujian Medical University

No. 134 Dong Street, Fuzhou 350001 (China)

E-Mail junpingwen@163.com 


\section{Kidney \\ Blood Pressure \\ Research}

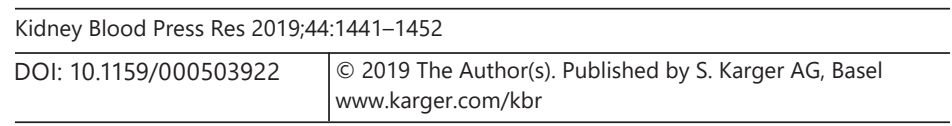

Lin et al.: Association between Depression and Renal Hyperfiltration

without depression (PHQ $<5$ ) or depressive episodes, those with clinically relevant depression $(\mathrm{PHQ} \geq 10)$ had a significantly higher risk of renal hyperfiltration. The fully adjusted OR (95\% $\mathrm{Cl}$ ) was 4.81 (1.62-14.30, $p=0.005)$, those with a major depressive episode had a higher risk of renal hyperfiltration (OR $7.45 ; 95 \% \mathrm{Cl} 2.04-27.21, p=0.002)$. Conclusion: Depressive symptoms and major depressive episodes are associated with renal hyperfiltration in middle-aged and elderly Chinese men without CKD. Future studies are needed to verify and clarify the role of depression in the development of abnormally high eGFR and CKD.

(C) 2019 The Author(s)

Published by S. Karger AG, Basel

\section{Introduction}

Emerging evidences have shown that depression and chronic kidney disease (CKD) may both affect large proportions of the global population. Depression is more common among patients with CKD than those without CKD. Symptoms including fatigue, anorexia, pain, muscle cramps, sleep disturbance, and sexual dysfunction lead to substantial impairments in the quality of life of CKD patients [1,2]. It was estimated that as many as $15-30 \%$ of patients with CKD may suffer from depression [3, 4], which is longitudinally associated with higher risks of adverse outcomes, including faster estimated glomerular filtration rate (eGFR) decrease, dialysis therapy initiation, death, or hospitalization [5-7]. Moreover, the presence of depression in various comorbidities, such as obesity, and diabetes, cardiovascular diseases, may further predict the poor renal and cardiovascular outcomes $[8,9]$.

However, data on the association between depression and earlier stages of CKD are scarce and conflicting. Albuminuria was associated with depressive symptoms and depressive episodes, even at levels that do not fulfil the CKD criteria [10]. The association between eGFR and depression remains unclear. Previous studies showed that eGFR may not be associated with depressive symptoms or major depressive episodes until it is moderately to severely reduced [11-13]. Several physiologic factors such as endothelial dysfunction, alterations in platelet reactivity, changes of the autonomic nervous system and hypothalamic pituitary adrenal axis, and dysregulation in immune response and inflammation in the setting of depression may explain the association between depression and albuminuria/decreased eGFR. On the other hand, increased GFR, also known as hyperfiltration, has been considered a predictor of renal function decline in various clinical conditions, including diabetes, hypertension, and obesity [14]. Renal hyperfiltration could be a novel marker of all-cause mortality [15] and be associated with coronary artery calcification [16]. Additionally, many lifestyle factors such as smoking [17], alcohol consumption [18], physical activity [19], and sleep duration [20] may be associated with renal hyperfiltration and predict the progression of albuminuria and CKD.

Currently, the association between depression and renal hyperfiltration in the general population remains unclear. In this study, we evaluated the association between depression and renal hyperfiltration in a large apparently healthy Chinese population.

\section{Methods}

\section{Setting and Study Population}

A population-based cross-sectional study was performed in Ningde, China, between June 2011 and January 2012. A total of 4,025 participants aged between 40 and 75 years were considered for inclusion in this study. The mean age of the participants in the present study was $53.8 \pm 9.0$ years. The current work was performed at Fujian Provincial Hospital, Fujian Medical University. 


\section{Kidney \\ Blood Pressure \\ Research}

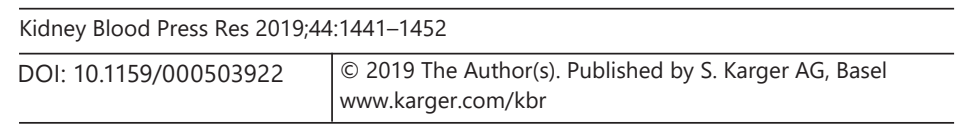

Lin et al.: Association between Depression and Renal Hyperfiltration

\section{Depressive Symptoms}

All participants were required to complete a self-reported structured questionnaire by a trained clinician. Depressive symptoms were assessed with a validated Chinese version of the 9-item Patient Health Questionnaire (PHQ-9) [21, 22]. The PHQ-9 is a self-administered questionnaire based on the Diagnostic and Statistical Manual of Mental Disorders, 4th edition (DSM-IV) criteria for a major depressive episode [23]. It comprises 9 items rated on a 4-point scale, ranging from 0 ("not at all") to 3 ("nearly every day"). As a continuous variable, scores 0-4 represent no or minimal, 5-9 represent mild, 10-14 represent moderate, 15-19 represent moderately severe, and 20-27 represent severe depression. A predefined cutoff score of $\geq 10$ was considered to indicate clinically relevant depressive symptoms in the preceding 2 weeks taking into account how well the participants understood the questionnaire [10].

\section{Minor and Major Depressive Episode}

The presence of a minor or major depressive episode was assessed by the Mini-International Neuropsychiatric Interview (MINI) according to the DSM-IV criteria [24]. A major depressive episode was diagnosed if participants had at least one core symptom (i.e., loss of interest or pleasure, feeling down or depressed) and at least four other symptoms of depression (i.e., insomnia or hypersomnia, fatigue or loss of energy, change in appetite and significant weight change, guilt or worthlessness, diminished ability to think or concentrate or indecisiveness, and suicidal thoughts or plans). Persons suffering from one core symptom and one to three other symptoms were considered to have a minor depressive episode.

\section{Measurements and Definition}

Blood samples were drawn after an overnight fast. Blood pressure was measured using an automated blood pressure measurement device (Omron Healthcare, Kyoto, Japan) after $10 \mathrm{~min}$ of rest, and the last two readings were averaged. The diagnosis of diabetes was based on the American Diabetes Association criteria, and hypertension was diagnosed according to the Eighth Joint National Commission recommendation or the use of antihypertensive medications. Serum creatinine was measured using the modified Jaffe reaction with a Beckman Analyzer (Beckman Instruments Inc., Fullerton, CA, USA). The serum creatinine measurement was reduced by $5 \%$ as previously proposed. eGFR was calculated with the Chronic Kidney Disease Epidemiology Collaboration (CKD-EPI) equation on the basis of serum creatinine. For the present analysis, renal hyperfiltration was defined as eGFR 95th percentile value of the whole population as previously suggested [15].

\section{Statistical Analyses}

All analyses were performed using SPSS 17.0 for windows (SPSS Inc., Chicago, IL, USA). $p<0.05$ (two sided) was considered statistically significant. All normally distributed continuous variables were presented as mean \pm standard deviation, and categorical variables were presented as percentages. Differences between two groups of continuous variables were compared using the $t$ test or the Mann-Whitney U test. Differences between categories were compared with one-way analysis of variance, $\chi^{2}$ and nonparametric tests as appropriate. Multiple logistic regression models were used to determine the odds ratio (OR) and 95\% confidence intervals (CIs) for the presence of clinically relevant depressive symptoms and major depressive episodes associated with renal hyperfiltration compared with the reference group in men and women, respectively. Subgroup analyses were performed for participants without risk factors associated with depression such as diabetes mellitus and hypertension. 
Table 1. Characteristics of the study population stratified by the presence of clinically relevant depressive symptoms and by the presence of a depressive episode

\begin{tabular}{|c|c|c|c|c|c|c|c|c|}
\hline \multirow[t]{2}{*}{ Characteristics } & \multicolumn{4}{|c|}{ Clinically relevant depressive symptoms (PHQ-9) } & \multicolumn{4}{|c|}{ Depressive episode } \\
\hline & PHQ $<5$ & $5 \leq \mathrm{PHQ}<10$ & PHQ $\geq 10$ & $p$ value $^{\mathrm{a}}$ & no & minor & major & $p$ value $^{\mathrm{a}}$ \\
\hline$n$ & 3,218 & 383 & 115 & & 3,594 & 64 & 58 & \\
\hline Age, years & $54.9 \pm 9.0$ & $54.9 \pm 8.9$ & $54.2 \pm 8.5$ & 0.721 & $54.9 \pm 9.0$ & $53.7 \pm 8.1$ & $54.7 \pm 9.3$ & 0.583 \\
\hline Men, \% & 36.4 & 26.6 & 26.1 & $<0.001$ & 35.2 & 32.8 & 27.6 & 0.448 \\
\hline BMI & $23.8 \pm 3.1$ & $23.3 \pm 3.1$ & $23.5 \pm 3.6$ & 0.012 & $24.2 \pm 3.2$ & $24.1 \pm 3.3$ & $23.5 \pm 3.5$ & 0.317 \\
\hline$<18.5, \%$ & 2.7 & 5 & 5.2 & 0.014 & 3 & 3.1 & 6.9 & 0.149 \\
\hline$\geq 25.0, \%$ & 32.3 & 27.7 & 24.3 & & 31.7 & 34.4 & 19 & \\
\hline Married/living with spouse, $\%$ & 91.8 & 88 & 88.7 & 0.026 & 91.4 & 92.2 & 86.2 & 0.371 \\
\hline Educational level, \% & & & & $<0.001$ & & & & 0.021 \\
\hline Low & 51.8 & 64.8 & 71.3 & & 53.2 & 65.6 & 70.7 & \\
\hline Intermediate & 42 & 29.8 & 23.5 & & 40.5 & 31.3 & 27.6 & \\
\hline High & 6.2 & 5.5 & 5.2 & & 6.3 & 3.1 & 1.7 & \\
\hline Systolic BP, mm Hg & $132.2 \pm 20.2$ & $129.8 \pm 19.3$ & $129.5 \pm 20.5$ & 0.036 & $131.9 \pm 20.1$ & $128.4 \pm 21.7$ & $130.5 \pm 20.0$ & 0.326 \\
\hline Diastolic BP, mm Hg & $75.2 \pm 10.9$ & $73.6 \pm 11.0$ & $74.7 \pm 10.9$ & 0.02 & $75.1 \pm 10.9$ & $73.3 \pm 12.1$ & $74.3 \pm 11.2$ & 0.377 \\
\hline $\mathrm{FSG}, \mathrm{mmol} / \mathrm{L}$ & $5.3 \pm 1.3$ & $5.3 \pm 1.4$ & $5.5 \pm 1.5$ & 0.398 & $5.3 \pm 1.3$ & $5.3 \pm 1.5$ & $5.4 \pm 1.0$ & 0.814 \\
\hline $\mathrm{HDL}, \mathrm{mmol} / \mathrm{L}$ & $1.3 \pm 0.4$ & $1.2 \pm 0.4$ & $1.2 \pm 0.4$ & 0.068 & $1.3 \pm 0.4$ & $1.2 \pm 0.4$ & $1.2 \pm 0.4$ & 0.066 \\
\hline LDL, mmol/L & $2.9 \pm 0.9$ & $2.8 \pm 0.9$ & $2.8 \pm 1.0$ & 0.001 & $2.9 \pm 0.9$ & $2.7 \pm 1.0$ & $2.6 \pm 0.8$ & 0.033 \\
\hline $\mathrm{CHOL}, \mathrm{mmol} / \mathrm{L}$ & $5.0 \pm 1.3$ & $4.7 \pm 1.3$ & $4.8 \pm 1.3$ & $<0.001$ & $5.0 \pm 1.3$ & $4.6 \pm 1.4$ & $4.6 \pm 1.2$ & 0.012 \\
\hline $\mathrm{TG}, \mathrm{mmol} / \mathrm{L}$ & $1.7 \pm 1.2$ & $1.5 \pm 0.9$ & $1.5 \pm 1.0$ & 0.019 & $1.4 \pm 1.0$ & $1.3 \pm 0.7$ & $1.5 \pm 1.1$ & 0.325 \\
\hline Serum creatinine, $\mathrm{mmol} / \mathrm{L}$ & $66.0 \pm 12.1$ & $62.1 \pm 11.1$ & $61.7 \pm 10.0$ & $<0.001$ & $65.6 \pm 12.0$ & $63.7 \pm 10.8$ & $60.6 \pm 8.7$ & 0.003 \\
\hline $\mathrm{eGFR}^{\mathrm{b}}, \mathrm{mL} / \mathrm{min} / 1.73 \mathrm{~m}^{2}$ & $96.4 \pm 11.9$ & $98.4 \pm 11.2$ & $99.0 \pm 11.3$ & $<0.001$ & $96.6 \pm 11.9$ & $98.5 \pm 9.9$ & $99.9 \pm 10.6$ & 0.051 \\
\hline $\mathrm{RHF}^{\mathrm{c}}, \%$ & 4.5 & 7.8 & 9.6 & 0.001 & 4.8 & 4.7 & 13.8 & 0.008 \\
\hline Smoking, \% & & & & 0.274 & & & & 0.839 \\
\hline Nonsmoker & 76.8 & 81.2 & 78.3 & & 77.3 & 78.1 & 79.3 & \\
\hline Former smoker & 7.6 & 5.2 & 5.2 & & 7.3 & 7.8 & 3.4 & \\
\hline Current smoker & 15.6 & 13.6 & 16.5 & & 15.4 & 14.1 & 17.2 & \\
\hline Alcohol consumption, $\%$ & & & & 0.207 & & & & 0.621 \\
\hline None & 54.7 & 52 & 58.3 & & 54.4 & 54.7 & 58.6 & \\
\hline Former drinker & 8.7 & 12 & 10.4 & & 9 & 12.5 & 12.1 & \\
\hline Current drinker & 36.6 & 36 & 31.3 & & 36.6 & 32.8 & 29.3 & \\
\hline Physical activity, \% & 18.2 & 15.5 & 13.5 & 0.065 & 18 & 21.7 & 12.7 & 0.285 \\
\hline Diabetes, $\%$ & 7.1 & 8.1 & 7.8 & 0.76 & 7.3 & 9.4 & 3.4 & 0.432 \\
\hline Hypertension, $\%$ & 17.8 & 23.8 & 22.6 & 0.01 & 18.4 & 18.8 & 27.6 & 0.205 \\
\hline \multicolumn{9}{|c|}{ Treatments for comorbid conditions, $\%$} \\
\hline Diabetes & 6.2 & 7.3 & 7 & 0.682 & 6.3 & 9.4 & 3.4 & 0.405 \\
\hline Hypertension & 12.3 & 14.6 & 13.9 & 0.396 & 12.5 & 15.6 & 13.8 & 0.731 \\
\hline Dyslipidemia & 0.6 & 0.0 & 0 & 0.228 & 0.5 & 0 & 0 & 0.723 \\
\hline Antidepressant medication & 0.1 & 0.0 & 0.0 & 0.734 & 0.1 & 0 & 0 & 0.934 \\
\hline
\end{tabular}

BMI, body mass index; BP, blood pressure; CHOL, cholesterol; eGFR, estimated glomerular filtration rate; FSG, fasting serum glucose; HDL, high-density lipoprotein; LDL, low-density lipoprotein; RHF, renal hyperfiltration; TG, triglyceride. ${ }^{a} \chi^{2}$ tests for discrete variables, Kruskal-Wallis tests for nonparametric variables, and one-way analysis of variance for continuous variables. ${ }^{\mathrm{b}}$ eGFR using the Chronic Kidney Disease Epidemiology Collaboration equation. ${ }^{\text {c }}$ GFR higher than the age-, sex-, BMI-, and the use of angiotensin-converting enzyme inhibitors or angiotensin II receptor blocker-adjusted 95th percentile (details in Methods).

\section{Results}

The mean age of the participants in the present study was $53.8 \pm 9.0$ years. Table 1 shows the general characteristics of the participants according to different categories of PHQ-9 or depressive episodes.

Overall, 115 participants had clinically relevant depressive symptoms. Compared with participants without depression ( $\mathrm{PHQ}<5$ ), participants with clinically relevant depressive symptoms (PHQ $\geq 10$ ) were more often women, less educated, had a lower level of diastolic 


\section{Research}

Lin et al.: Association between Depression and Renal Hyperfiltration

Table 2. Characteristics of individuals with and without RHF

\begin{tabular}{|c|c|c|c|}
\hline & Without RHF & With RHF & $p$ value $^{\mathrm{a}}$ \\
\hline$n$ & 3,531 & 185 & \\
\hline Age, years & $54.7 \pm 8.5$ & $57.4 \pm 8.5$ & $<0.001$ \\
\hline Men, \% & 34.4 & 48.6 & $<0.001$ \\
\hline BMI & $23.7 \pm 3.1$ & $23.7 \pm 3.7$ & 0.969 \\
\hline$<18.5, \%$ & 2.8 & 7 & 0.003 \\
\hline$\geq 25.0, \%$ & 31.5 & 34.1 & \\
\hline Married/living with spouse, $\%$ & 91.1 & 95.1 & 0.06 \\
\hline \multicolumn{4}{|l|}{ Educational level, \% } \\
\hline Low & 53.4 & 77.8 & $<0.001$ \\
\hline Intermediate & 41.2 & 20 & \\
\hline High & 6.3 & 2.2 & \\
\hline Systolic BP, mm Hg & $131.9 \pm 20.1$ & $130.3 \pm 20.1$ & 0.272 \\
\hline Diastolic BP, mm Hg & $75.2 \pm 10.9$ & $71.7 \pm 10.6$ & $<0.001$ \\
\hline $\mathrm{FSG}, \mathrm{mmol} / \mathrm{L}$ & $5.3 \pm 1.3$ & $5.8 \pm 1.7$ & $<0.001$ \\
\hline $\mathrm{HDL}, \mathrm{mmol} / \mathrm{L}$ & $1.3 \pm 0.4$ & $0.9 \pm 0.3$ & $<0.001$ \\
\hline $\mathrm{LDL}, \mathrm{mmol} / \mathrm{L}$ & $3.0 \pm 0.9$ & $1.8 \pm 0.7$ & $<0.001$ \\
\hline CHOL, mmol/L & $5.0 \pm 1.2$ & $3.2 \pm 1.1$ & $<0.001$ \\
\hline $\mathrm{TG}, \mathrm{mmol} / \mathrm{L}$ & $1.4 \pm 1.0$ & $0.9 \pm 0.6$ & $<0.001$ \\
\hline Serum creatinine, $\mathrm{mmol} / \mathrm{L}$ & $66.4 \pm 11.4$ & $47.1 \pm 6.4$ & $<0.001$ \\
\hline $\mathrm{eGFR}^{\mathrm{b}}, \mathrm{mL} / \mathrm{min} / 1.73 \mathrm{~m}^{2}$ & $95.9 \pm 11.5$ & $111.3 \pm 8.4$ & $<0.001$ \\
\hline Smoking, \% & & & 0.072 \\
\hline Nonsmoker & 77.6 & 70.8 & \\
\hline Former smoker & 7.2 & 8.1 & \\
\hline Current smoker & 15.2 & 21.1 & \\
\hline Alcohol consumption, \% & & & 0.118 \\
\hline None & 54.8 & 49.2 & \\
\hline Former drinker & 8.9 & 13 & \\
\hline Current drinker & 36.3 & 37.8 & \\
\hline Physical activity, \% & 18.4 & 14.7 & 0.168 \\
\hline Depressive symptoms, $\%$ & & & 0.001 \\
\hline PHQ $\geq 10$ & 2.9 & 5.9 & \\
\hline $5 \leq \mathrm{PHQ}<10$ & 10 & 16.2 & \\
\hline $\mathrm{PHQ}<5$ & 87.1 & 77.8 & \\
\hline Depressive episode, \% & & & 0.008 \\
\hline Major & 1.4 & 4.3 & \\
\hline Minor & 1.7 & 1.6 & \\
\hline No & 96.9 & 94.1 & \\
\hline Diabetes, \% & 7.1 & 10.8 & 0.059 \\
\hline Hypertension, \% & 18.6 & 18.9 & 0.923 \\
\hline \multicolumn{4}{|c|}{ Treatments for comorbid conditions, $\%$} \\
\hline Diabetes & 6.3 & 7.6 & 0.441 \\
\hline Hypertension & 12.5 & 14.6 & 0.425 \\
\hline Dyslipidemia & 0.5 & 0.5 & 1 \\
\hline Antidepressant medication & 0.1 & 0 & 1 \\
\hline
\end{tabular}

BMI, body mass index; $\mathrm{BP}$, blood pressure; $\mathrm{CHOL}$, cholesterol; eGFR, estimated glomerular filtration rate; FSG, fasting serum glucose; HDL, high-density lipoprotein; LDL, low-density lipoprotein; RHF, renal hyperfiltration; TG, triglyceride. ${ }^{a} \chi^{2}$ for discrete variables, Kruskal-Wallis tests for nonparametric variables, and one-way analysis of variance for continuous variables. ${ }^{\mathrm{b}}$ eGFR using the Chronic Kidney Disease Epidemiology Collaboration equation. 
Table 3. Multiple adjusted ORs ( $95 \% \mathrm{CI}$ ) of renal hyperfiltration across depressive symptoms categories

\begin{tabular}{|c|c|c|c|c|c|c|}
\hline \multirow[t]{2}{*}{ PHQ-9 } & \multicolumn{2}{|l|}{ Model 1} & \multicolumn{2}{|l|}{ Model 2} & \multicolumn{2}{|l|}{ Model 3} \\
\hline & OR $(95 \% \mathrm{CI})$ & $\begin{array}{l}p \\
\text { value }\end{array}$ & OR $(95 \% \mathrm{CI})$ & $\begin{array}{l}p \\
\text { value }\end{array}$ & OR $(95 \% \mathrm{CI})$ & $\begin{array}{l}p \\
\text { value }\end{array}$ \\
\hline \multicolumn{7}{|l|}{ Men $(n=1,303)$} \\
\hline PHQ $\geq 10$ & $4.72(1.96-11.36)$ & 0.001 & $4.34(1.73-10.88)$ & 0.002 & $4.81(1.62-14.30)$ & 0.005 \\
\hline $5 \leq \mathrm{PHQ}<10$ & $2.07(1.08-3.95)$ & 0.028 & $1.98(1.00-3.91)$ & 0.049 & $1.22(0.56-2.64)$ & 0.614 \\
\hline PHQ $<5$ & ref & & ref & & ref & \\
\hline \multicolumn{7}{|c|}{ Women $(n=2,413)$} \\
\hline PHQ $\geq 10$ & $1.34(0.48-3.74)$ & 0.582 & $1.13(0.40-3.23)$ & 0.817 & $1.07(0.34-3.33)$ & 0.909 \\
\hline $5 \leq \mathrm{PHQ}<10$ & $1.85(1.09-3.15)$ & 0.023 & $1.63(0.94-2.82)$ & 0.081 & $1.18(0.63-2.21)$ & 0.603 \\
\hline $\mathrm{PHQ}<5$ & ref & & ref & & ref & \\
\hline
\end{tabular}

Model 1, unadjusted; Model 2, adjustment for age, BMI, current smoking, alcohol intake, and exercise; Model 3, model 2 + systolic BP, diastolic BP, fasting glucose, LDL cholesterol, HDL cholesterol, triglyceride.

blood pressure and triglyceride, and a higher proportion of renal hyperfiltration and underweight. Characteristics of the subpopulation with a major depressive episode (Table 1) were similar. 58 participants had a major depressive episode, and 64 participants had a minor depressive episode. Compared with those participants without depressive episodes, participants with a major depressive episode were also less educated, more often underweight, had a lower level of low-density lipoprotein and cholesterol, and a higher proportion of renal hyperfiltration. No difference in self-reported medications, particularly antidiabetic agents, antihypertensive agents, lipid-regulating drugs, and antidepressant agents, was observed across all the depressive categories.

Table 2 shows the characteristics of participants with renal hyperfiltration compared with those without renal hyperfiltration. In general, 90 men and 95 women with hyperfiltration had mean eGFRs of 112.1 (range 95.5-140.9) and 110.5.2 (range 94.1-128.33.2) mL/ $\min / 1.73 \mathrm{~m}^{2}$, respectively, compared with 94.6 (range 60.14-125.32) and 96.7 (range 60.4123.5) $\mathrm{mL} / \mathrm{min} / 1.73 \mathrm{~m}^{2}$ for men and women without renal hyperfiltration, respectively. Participants with renal hyperfiltration were older, more often male, had a lower level of triglyceride, cholesterol, high-density lipoprotein, and diastolic blood pressure, had a higher proportion of overweight and underweight, a higher proportion of symptomatic depression and major depressive episodes.

The association between depression and renal hyperfiltration was analyzed using a multivariate logistic regression adjusted for possible confounding variables, such as age, sex, smoking status, alcohol intake, diabetes, hypertension, dyslipidemia, BMI, systolic blood pressure, diastolic blood pressure, fasting glucose, and vigorous physical activities. As shown in Table 3, the association between clinically relevant depression and renal hyperfiltration remained significant in men but not in women after adjustment for all confounders (model $3)$. As compared with men without depression ( $\mathrm{PHQ}<5)$, those with renal clinically relevant depression (PHQ $\geq 10$ ) had a significantly higher risk of renal hyperfiltration. The fully adjusted OR (95\% CI) was 4.81(1.62-14.30, $p=0.005)$. Similarly, as shown in Table 4, men with major depressive episodes had a higher risk of renal hyperfiltration than those without a depressive episode. The adjusted OR (95\% CI) was $7.45(2.04-27.21, p=0.002)$. In addition, renal hyperfiltration was significantly associated with age and diastolic blood pressure for men, and was associated with fasting glucose, age, triglyceride, and BMI for women. The logistic regression models were repeated with a definition of hyperfiltration by defining 
Table 4. Multiple adjusted ORs ( $95 \% \mathrm{CI}$ ) of renal hyperfiltration across depressive episodes categories

\begin{tabular}{|c|c|c|c|c|c|c|}
\hline \multirow{2}{*}{$\begin{array}{l}\text { Depressive } \\
\text { episode }\end{array}$} & \multicolumn{2}{|l|}{ Model 1} & \multicolumn{2}{|l|}{ Model 2} & \multicolumn{2}{|l|}{ Model 3} \\
\hline & OR $(95 \% \mathrm{CI})$ & $\begin{array}{l}p \\
\text { value }\end{array}$ & OR $(95 \% \mathrm{CI})$ & $\begin{array}{l}p \\
\text { value }\end{array}$ & OR $(95 \% \mathrm{CI})$ & $\begin{array}{l}p \\
\text { value }\end{array}$ \\
\hline \multicolumn{7}{|c|}{ Men $(n=1,303)$} \\
\hline Major & $8.55(3.03-24.11)$ & $<0.001$ & $9.04(3.03-27.01)$ & $<0.001$ & $7.45(2.04-27.21)$ & 0.002 \\
\hline $\begin{array}{l}\text { Minor } \\
\text { No }\end{array}$ & $\begin{array}{l}0.71(0.09-5.38) \\
\text { ref }\end{array}$ & 0.742 & $\begin{array}{l}0.73(0.09-5.65) \\
\text { ref }\end{array}$ & 0.76 & $\begin{array}{l}0.92(0.11-7.88) \\
\text { ref }\end{array}$ & 0.94 \\
\hline \multicolumn{7}{|c|}{ Women $(n=2,413)$} \\
\hline Major & $1.23(0.29-5.17)$ & 0.778 & $1.24(0.29-5.34)$ & 0.772 & $1.03(0.22-4.96)$ & 0.968 \\
\hline Minor & $1.20(0.29-5.03)$ & 0.804 & $1.11(0.26-4.74)$ & 0.892 & $\begin{array}{l}0.54(0.12-2.55) \\
\text { ref }\end{array}$ & 0.541 \\
\hline
\end{tabular}

Model 1, unadjusted; Model 2, adjustment for age, BMI, current smoking, alcohol intake, and exercise; Model 3, model 2 + systolic BP, diastolic BP, fasting glucose, LDL cholesterol, HDL cholesterol, triglyceride, cholesterol.

Table 5. Multiple adjusted ORs (95\% CI) of renal hyperfiltration across different subgroups

\begin{tabular}{|c|c|c|c|c|c|c|}
\hline Subgroup & PHQ-9 & OR (95\% CI) & $\begin{array}{l}p \\
\text { value }\end{array}$ & $\begin{array}{l}\text { Depressive } \\
\text { episode }\end{array}$ & OR (95\% CI) & $\begin{array}{l}p \\
\text { value }\end{array}$ \\
\hline $\begin{array}{l}\text { Without hypertension } \\
(n=1,066)\end{array}$ & $\begin{array}{l}\mathrm{PHQ} \geq 10 \\
5 \leq \mathrm{PHQ}<10 \\
\mathrm{PHQ}<5\end{array}$ & $\begin{array}{l}3.523(0.930-13.350) \\
0.765(0.290-2.016) \\
\text { ref }\end{array}$ & $\begin{array}{l}0.064 \\
0.587\end{array}$ & $\begin{array}{l}\text { major } \\
\text { minor } \\
\text { no }\end{array}$ & $\begin{array}{l}7.467(1.856-30.045) \\
0.631(0.054-7.365) \\
\text { ref }\end{array}$ & $\begin{array}{l}0.005 \\
0.713\end{array}$ \\
\hline $\begin{array}{l}\text { Without diabetes } \\
(n=1,190)\end{array}$ & $\begin{array}{l}\mathrm{PHQ} \geq 10 \\
5 \leq \mathrm{PHQ}<10 \\
\mathrm{PHQ}<5\end{array}$ & $\begin{array}{l}5.254(1.623-17.003) \\
1.312(0.592-2.908) \\
\text { ref }\end{array}$ & $\begin{array}{l}0.006 \\
0.504\end{array}$ & $\begin{array}{l}\text { major } \\
\text { minor } \\
\text { no }\end{array}$ & $\begin{array}{l}5.143(1.012-26.152) \\
0.615(0.052-7.344) \\
\text { ref }\end{array}$ & $\begin{array}{l}0.048 \\
0.615\end{array}$ \\
\hline
\end{tabular}

Adjustment for age, BMI, current smoking, alcohol intake and exercise, educational level, marital status, systolic BP, diastolic BP, fasting glucose, LDL cholesterol, HDL cholesterol, triglyceride, cholesterol and hypertension or diabetes.

those with adjusted absolute GFR >90th percentile as having hyperfiltration (data not shown). These analyses yielded similar findings.

Multivariate logistic analysis was also performed in men without major risk factors for renal hyperfiltration. After adjustment of all the confounders, renal hyperfiltration was associated with clinically relevant depression in participants without diabetes (OR 5.254, 95\% CI 1.623-17.003; $p=0.006$ ) (Table 5). Symptomatic depression had a trend to be associated with renal hyperfiltration in participants without hypertension, but it did not reach statistical significance. On the other hand, major depressive episodes were associated with renal hyperfiltration in participants without diabetes (OR 7.467, 95\% CI 1.856-30.045; $p=0.005$ ) and participants without hypertension (OR 5.143, 95\% CI 1.012-26.152; $p=0.048$ ).

\section{Discussion}

In this study, we identified an association between clinically relevant depression and major depressive episodes and the incidence of renal hyperfiltration in an apparently healthy population from a community in China. Self-reported depressive symptoms and major 


\section{Kidney \\ Blood Pressure \\ Research}

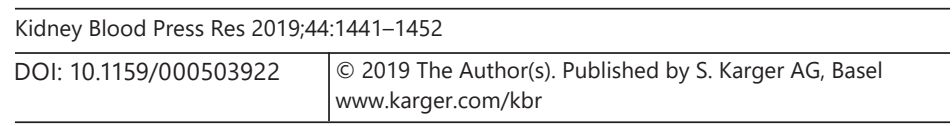

Lin et al.: Association between Depression and Renal Hyperfiltration

depressive episodes were associated with renal hyperfiltration in men but not in women. This relationship was valid even after adjustment for a variety of confounding or explanatory variables such as hypertension and diabetes.

It has been well documented that the high prevalence of depression is an independent risk factor of poor outcomes even in patients with CKD before dialysis [5], as well as renal transplantation [25]. The relationships between depression and eGFR have been investigated in a number of previous studies which concentrated on low eGFR. In a cohort without substantial CKD, albuminuria but not eGFR was shown to be associated with depression [10]. Whether depression is also associated with the progression of earlier stages of CKD remains unknown. Recently, in a large prospective cohort study of US veterans with diabetes and eGFR $\geq 60 \mathrm{~mL} / \mathrm{min} / 1.73 \mathrm{~m}^{2}$, Novak et al. [8] demonstrated that patients with depression at baseline had higher eGFR and more comorbidities. During the follow-up period, the presence of depression was associated with a higher risk of incident CKD and high all-cause mortality, incident cardiac events, and incident stroke [8]. It is unclear whether depression could be independently associated with renal hyperfiltration in the general population. Several cardiometabolic factors such as high blood pressure, left ventricular hypertrophy, microalbuminuria, and coronary artery calcification may explain the high all-cause mortality associated with renal hyperfiltration recently ascertained in a number of recent studies [16, 26]. Renal hyperfiltration might be the missing link between cardiorenal risk factors and CKD or cardiovascular disease. The bidirectional relationships between depression and cardiometabolic disease such as diabetes, metabolic syndrome, and cardiovascular diseases have been proofed in several population-based studies [2729]. To date, no study has yet reported the association between depression and renal hyperfiltration. To address this issue, we performed a cross-sectional study in a large general Chinese population without CKD.

The results of this study differ from a recent population-based study that have shown no association between depression and eGFR in participants with normal or mildly reduced eGFR. However, that study only concentrated on the risk of depressive symptoms per $10 \mathrm{~mL} /$ $\mathrm{min} / 1.73 \mathrm{~m}^{2}$ lower eGFR but not in subgroups with renal hyperfiltration [10]. Previous studies that have examined health-related quality of life (HRQoL) and depression in patients with CKD showed that the stronger effect of lower eGFR on depressive symptoms may attribute to the increased cardiovascular disease present at CKD [12]. In this study, patients with a known history of cardiovascular disease were excluded on inclusion. Renal hyperfiltration is a characteristic functional abnormality in comorbid conditions such as diabetes, hypertension, and obesity; depressive symptoms and major depressive episodes are also associated with those comorbidities [30-34]. The association between renal hyperfiltration and depressive symptoms might in part be confounded by the indirect effect of diabetes and hypertension. However, the association remained significant in the subgroup analysis of participants without diabetes or hypertension. Therefore, it is unlikely that diabetes or hypertension mainly contribute to depression in this study.

In this study, eGFR was evaluated on the basis of serum creatinine, it could not be excluded that high eGFR might be a manifestation of decreased muscle mass but not truly high GFR. Previous studies have shown that low body mass and sarcopenia were associated with depression in elderly men [35]. Because participants with a BMI $<18.5$ had a greater possibility of muscle wasting than those with a BMI $\geq 18.5$ [36]. In this study, the association between depression with high GFR did not change after participants with a BMI $<18.5$ were excluded (data not shown).

Consistent with previous studies that showed a higher prevalence of major depression in women than men, a major depressive episode and symptomatic depression were more common in women than in men in this study [37]. However, depression was found to be 
Kidney
Blood Pressure

Research

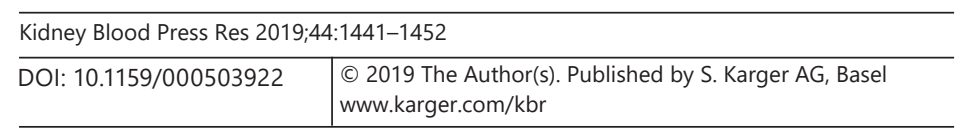

Lin et al.: Association between Depression and Renal Hyperfiltration

related to renal hyperfiltration in men, but not in women. Similarly, the gender differences in depression as a risk factor for comorbid diseases have been reported in previous studies [38-40]. For example, In the National Health and Nutrition Examination Survey, cardiovascular disease mortality was only related to depression in men, while depression had no effect on cardiovascular disease mortality in women [39]. Increasing inflammation predicted by the depressive symptoms for men, but not for women, may partially explain the gender-related finding.

A potential explanation that connects high eGFR and depression could be low-grade inflammation and endothelial cell dysfunction. A variety of vasoactive mediators including the nitric oxide system, cyclooxygenase 2 (COX2)-derived prostanoids, protein kinase $\mathrm{C}$, and endothelin may contribute to the renal hyperfiltration [41]. Inflammatory cytokines and adipokines were also associated with glomerular hyperfiltration. A number of these inflammatory markers have been consistently associated with endothelial cell dysfunction and depression. Indeed, depressed patients have been found to have high levels of inflammatory markers, such as C-reactive protein, interleukin 1, 2, 6, and tumor necrosis factor, and endothelial chemokines, such as sICAM-1, sE-Selectin [42-44]. In addition, renin-angiotensin system (RAS) activation in glomerular hyperfiltration patients may also play a role in depression. AGTR1, the gene coding for the type 1 angiotensin II receptor (AT1R), has been shown to be associated with a diagnosis of depression [45]. Furthermore, increased sympathetic nerve activity to the kidney and the renal afferent nerve activity to the central nervous system may also contribute to the development of depression.

The major strengths of our study include its large sample size of the general population, detailed epidemiologic profiles, and thorough statistical analyses. However, there are several limitations. First, the results might be biased because GFR was estimated using serum creatinine-based (CKD-EPI) equation rather than direct measurement or CKD-EPI creat-cys calculation. In the current study, renal hyperfiltration was defined after adjustment for age, sex, $\mathrm{BMI}$, and angiotensin-converting-enzyme inhibitors (ACEI)/angiotensin receptor blocker (ARB)treatment. Nevertheless, it does not completely avoid overestimating GFR, especially in participants with muscle waste. Second, information on depression relies on self-reports, which could lead to recall bias and misclassification. We also performed an interview to assess minor and major depressive episodes. Consistent with other depression screening scales, the item responses and total scores on the PHQ-9 follow the same characteristic patterns, which may serve as a basis for the estimation of the distribution of depression in a general population [46]. In the current study, 3.1\% of participants had clinically relevant depression and 3.3\% had major or minor depressive episodes. The result was similar to other studies that were performed in a general population of China $[47,48]$. Third, although patients with a known history of CKD including eGFR $<60 \mathrm{~mL} / \mathrm{min} / 1.73 \mathrm{~m}^{2}$, or dipstick proteinuria $\geq 1+$ or ACR (albumin creatinine ratio) $\geq 30 \mathrm{mg} / \mathrm{g}$ had been excluded on inclusion, we could not evaluate the effect of proteinuria at levels that do not fulfil the CKD criteria in this study. Fourth, although we have adjusted for several confounders that could explain the relationship between depression and renal hyperfiltration, it is possible that residual factors not captured in this study could lead to misclassification of depression. Additionally, the cross-sectional design limits causal inference. Follow-up studies are required to examine the long-term effect of depression on proteinuria and incidence of CKD in this population. This study might not represent the general population in China, and we should be cautious in generalizing the results.

In conclusion, our study is novel in demonstrating the associations between depression and renal hyperfiltration in middle-aged and elderly men, and this relationship was independent of diabetes and hypertension. Whether depression could be a modifiable factor in the development of renal hyperfiltration and CKD with cardiometabolic risk factors warrants further investigation. 


\section{Kidney \\ Blood Pressure Research}

\begin{tabular}{l|l}
\hline Kidney Blood Press Res 2019:44:1441-1452 \\
\hline DOI: 10.1159/000503922 & $\begin{array}{l}\text { @ 2019 The Author(s). Published by S. Karger AG, Basel } \\
\text { www.karger.com/kbr }\end{array}$ \\
\hline
\end{tabular}

Lin et al.: Association between Depression and Renal Hyperfiltration

\section{Acknowledgements}

This study was supported by grants from the Chinese Medical Association Foundation and Chinese Endocrine Society (12020240314), National Key New Drug Creation and Manufacturing Program of Ministry of Science and Technology (2012ZX09303006-001), Joint Science and Technology Innovation Fund of Fujian province (No.2016Y9001), and Key Clinical Specialty Discipline Construction Program of Fujian, China.

\section{Statement of Ethics}

The study protocol was approved by the Ethics Committee of Fujian Provincial Hospital in accordance with the Declaration of Helsinki, and written informed consent was obtained from each participant.

\section{Disclosure Statement}

The authors declare no conflict of interest.

\section{References}

1 Evans RW, Manninen DL, Garrison LP Jr, Hart LG, Blagg CR, Gutman RA, et al. The quality of life of patients with end-stage renal disease. N Engl J Med. 1985 Feb;312(9):553-9.

2 Murtagh FE, Addington-Hall JM, Edmonds PM, Donohoe P, Carey I, Jenkins K, et al. Symptoms in advanced renal disease: a cross-sectional survey of symptom prevalence in stage 5 chronic kidney disease managed without dialysis. J Palliat Med. 2007 Dec;10(6):1266-76.

3 Palmer S, Vecchio M, Craig JC, Tonelli M, Johnson DW, Nicolucci A, et al. Prevalence of depression in chronic kidney disease: systematic review and meta-analysis of observational studies. Kidney Int. 2013 Jul;84(1): 179-91.

4 Cohen SD, Norris L, Acquaviva K, Peterson RA, Kimmel PL. Screening, diagnosis, and treatment of depression in patients with end-stage renal disease. Clin J Am Soc Nephrol. 2007 Nov;2(6):1332-42.

5 Hedayati SS, Minhajuddin AT, Afshar M, Toto RD, Trivedi MH, Rush AJ. Association between major depressive episodes in patients with chronic kidney disease and initiation of dialysis, hospitalization, or death. JAMA. 2010 May;303(19):1946-53.

6 Tsai YC, Chiu YW, Hung CC, Hwang SJ, Tsai JC, Wang SL, et al. Association of symptoms of depression with progression of CKD. Am J Kidney Dis. 2012 Jul;60(1):54-61.

7 Molnar MZ, Streja E, Sumida K, Soohoo M, Ravel VA, Gaipov A, et al. Pre-ESRD Depression and Post-ESRD Mortality in Patients with Advanced CKD Transitioning to Dialysis. Clin J Am Soc Nephrol. 2017 Sep;12(9): 1428-37.

8 Novak M, Mucsi I, Rhee CM, Streja E, Lu JL, Kalantar-Zadeh K, et al. Increased Risk of Incident Chronic Kidney Disease, Cardiovascular Disease, and Mortality in Patients With Diabetes With Comorbid Depression. Diabetes Care. 2016 Nov;39(11):1940-7.

9 Hedayati SS, Jiang W, O'Connor CM, Kuchibhatla M, Krishnan KR, Cuffe MS, et al. The association between depression and chronic kidney disease and mortality among patients hospitalized with congestive heart failure. Am J Kidney Dis. 2004 Aug;44(2):207-15.

10 Martens RJ, Kooman JP, Stehouwer CD, Dagnelie PC, van der Kallen CJ, Kroon AA, et al. Albuminuria is associated with a higher prevalence of depression in a population-based cohort study: the Maastricht Study. Nephrol Dial Transplant. 2018 Jan;33(1):128-38.

11 Fischer MJ, Xie D, Jordan N, Kop WJ, Krousel-Wood M, Kurella Tamura M, et al.; CRIC Study Group Investigators. Factors associated with depressive symptoms and use of antidepressant medications among participants in the Chronic Renal Insufficiency Cohort (CRIC) and Hispanic-CRIC Studies. Am J Kidney Dis. 2012 Jul;60(1): 27-38.

12 Campbell KH, Huang ES, Dale W, Parker MM, John PM, Young BA, et al. Association between estimated GFR, health-related quality of life, and depression among older adults with diabetes: the Diabetes and Aging Study. Am J Kidney Dis. 2013 Sep;62(3):541-8.

13 Hedayati SS, Minhajuddin AT, Toto RD, Morris DW, Rush AJ. Prevalence of major depressive episode in CKD. Am J Kidney Dis. 2009 Sep; 54(3):424-32. 
Lin et al.: Association between Depression and Renal Hyperfiltration

14 Helal I, Fick-Brosnahan GM, Reed-Gitomer B, Schrier RW. Glomerular hyperfiltration: definitions, mechanisms and clinical implications. Nat Rev Nephrol. 2012 Feb;8(5):293-300.

15 Park M, Yoon E, Lim YH, Kim H, Choi J, Yoon HJ. Renal hyperfiltration as a novel marker of all-cause mortality. J Am Soc Nephrol. 2015 Jun;26(6):1426-33.

16 Choi HM, Hyun YY, Lee KB, Kim H. High estimated glomerular filtration rate is associated with coronary artery calcification in middle-aged Korean men without chronic kidney disease. Nephrol Dial Transplant. 2015 Jun; $30(6): 996-1001$.

17 Maeda I, Hayashi T, Sato KK, Koh H, Harita N, Nakamura Y, et al. Cigarette smoking and the association with glomerular hyperfiltration and proteinuria in healthy middle-aged men. Clin J Am Soc Nephrol. 2011 Oct; 6(10):2462-9.

18 Lin M, Su Q, Huang H, Zheng Y, Wen J, Yao J, et al. Alcohol consumption and the risk for renal hyperfiltration in the general Chinese population. Eur J Clin Nutr. 2017 Apr;71(4):500-5.

19 Melsom T, Mathisen UD, Eilertsen BA, Ingebretsen OC, Jenssen T, Njølstad I, et al. Physical exercise, fasting glucose, and renal hyperfiltration in the general population: the Renal Iohexol Clearance Survey in Tromsø 6 (RENIS-T6). Clin J Am Soc Nephrol. 2012 Nov;7(11):1801-10.

20 Lin M, Su Q, Wen J, Wei S, Yao J, Huang H, et al. Self-reported sleep duration and daytime napping are associated with renal hyperfiltration in general population. Sleep Breath. 2018 Mar;22(1):223-32.

21 Spitzer RL, Kroenke K, Williams JB; Primary Care Evaluation of Mental Disorders. Validation and utility of a self-report version of PRIME-MD: the PHQ primary care study. Primary Care Evaluation of Mental Disorders. Patient Health Questionnaire. JAMA. 1999 Nov;282(18):1737-44.

22 Xiong N, Fritzsche K, Wei J, Hong X, Leonhart R, Zhao X, et al. Validation of patient health questionnaire (PHQ) for major depression in Chinese outpatients with multiple somatic symptoms: a multicenter cross-sectional study. J Affect Disord. 2015 Mar;174:636-43.

23 Kroenke K, Spitzer RL, Williams JB. The PHQ-9: validity of a brief depression severity measure. J Gen Intern Med. 2001 Sep;16(9):606-13.

24 Sheehan DV, Lecrubier Y, Sheehan KH, Amorim P, Janavs J, Weiller E, et al. The Mini-International Neuropsychiatric Interview (M.I.N.I.): the development and validation of a structured diagnostic psychiatric interview for DSM-IV and ICD-10. J Clin Psychiatry. 1998;59 Suppl 20:22-33.

25 Szeifert L, Molnar MZ, Ambrus C, Koczy AB, Kovacs AZ, Vamos EP, et al. Symptoms of depression in kidney transplant recipients: a cross-sectional study. Am J Kidney Dis. 2010 Jan;55(1):132-40.

26 Di Bonito P, Sanguigno E, Forziato C, Di Fraia T, Moio N, Cavuto L, et al. Glomerular filtration rate and cardiometabolic risk in an outpatient pediatric population with high prevalence of obesity. Obesity (Silver Spring). 2014 Feb;22(2):585-9.

27 Golden SH, Lazo M, Carnethon M, Bertoni AG, Schreiner PJ, Diez Roux AV, et al. Examining a bidirectional association between depressive symptoms and diabetes. JAMA. 2008 Jun;299(23):2751-9.

28 Pan A, Keum N, Okereke OI, Sun Q, Kivimaki M, Rubin RR, et al. Bidirectional association between depression and metabolic syndrome: a systematic review and meta-analysis of epidemiological studies. Diabetes Care. 2012 May;35(5):1171-80.

29 Lippi G, Montagnana M, Favaloro EJ, Franchini M. Mental depression and cardiovascular disease: a multifaceted, bidirectional association. Semin Thromb Hemost. 2009 Apr;35(3):325-36.

30 Pereira-Miranda E, Costa PR, Queiroz VA, Pereira-Santos M, Santana ML. Overweight and Obesity Associated with Higher Depression Prevalence in Adults: A Systematic Review and Meta-Analysis. J Am Coll Nutr. 2017 Mar-Apr;36(3):223-33.

31 de Wit LM, van Straten A, van Herten M, Penninx BW, Cuijpers P. Depression and body mass index, a u-shaped association. BMC Public Health. 2009 Jan;9(1):14.

32 Pan A, Lucas M, Sun Q, van Dam RM, Franco OH, Manson JE, et al. Bidirectional association between depression and type 2 diabetes mellitus in women. Arch Intern Med. 2010 Nov;170(21):1884-91.

33 Davidson K, Jonas BS, Dixon KE, Markovitz JH. Do depression symptoms predict early hypertension incidence in young adults in the CARDIA study? Coronary Artery Risk Development in Young Adults. Arch Intern Med. 2000 May;160(10):1495-500.

34 Meng L, Chen D, Yang Y, Zheng Y, Hui R. Depression increases the risk of hypertension incidence: a metaanalysis of prospective cohort studies. J Hypertens. 2012 May;30(5):842-51.

35 Kim NH, Kim HS, Eun CR, Seo JA, Cho HJ, Kim SG, et al. Depression is associated with sarcopenia, not central obesity, in elderly korean men. J Am Geriatr Soc. 2011 Nov;59(11):2062-8.

36 Pasco JA, Holloway KL, Dobbins AG, Kotowicz MA, Williams LJ, Brennan SL. Body mass index and measures of body fat for defining obesity and underweight: a cross-sectional, population-based study. BMC Obes. 2014 Jun; 1(1):9.

37 Piccinelli M, Wilkinson G. Gender differences in depression. Critical review. Br J Psychiatry. 2000 Dec;177(6): 486-92.

38 Ferketich AK, Schwartzbaum JA, Frid DJ, Moeschberger ML. Depression as an antecedent to heart disease among women and men in the NHANES I study. National Health and Nutrition Examination Survey. Arch Intern Med. 2000 May;160(9):1261-8.

39 Penninx BW, Guralnik JM, Mendes de Leon CF, Pahor M, Visser M, Corti MC, et al. Cardiovascular events and mortality in newly and chronically depressed persons [\{GT\}] 70 years of age. Am J Cardiol. 1998 Apr;81(8): 988-94. 
40 Appelman Y, van Rijn BB, Ten Haaf ME, Boersma E, Peters SA. Sex differences in cardiovascular risk factors and disease prevention. Atherosclerosis. 2015 Jul;241(1):211-8.

41 Sasson AN, Cherney DZ. Renal hyperfiltration related to diabetes mellitus and obesity in human disease. World J Diabetes. 2012 Jan;3(1):1-6.

42 Rajagopalan S, Brook R, Rubenfire M, Pitt E, Young E, Pitt B: Abnormal brachial artery flow-mediated vasodilation in young adults with major depression. Am J Cardiol. 2001 Jul;88(2):196-8, A197.

43 van Dooren FE, Schram MT, Schalkwijk CG, Stehouwer CD, Henry RM, Dagnelie PC, et al. Associations of low grade inflammation and endothelial dysfunction with depression - The Maastricht Study. Brain Behav Immun. 2016 Aug;56:390-6.

44 Do DP, Dowd JB, Ranjit N, House JS, Kaplan GA. Hopelessness, depression, and early markers of endothelial dysfunction in U.S. adults. Psychosom Med. 2010 Sep;72(7):613-9.

45 Taylor WD, Benjamin S, McQuoid DR, Payne ME, Krishnan RR, MacFall JR, et al. AGTR1 gene variation: association with depression and frontotemporal morphology. Psychiatry Res. 2012 May;202(2):104-9.

46 Tomitaka S, Kawasaki Y, Ide K, Akutagawa M, Yamada H, Ono Y, et al. Distributional patterns of item responses and total scores on the PHQ-9 in the general population: data from the National Health and Nutrition Examination Survey. BMC Psychiatry. 2018 Apr;18(1):108.

47 Chen R, Copeland JR, Wei L. A meta-analysis of epidemiological studies in depression of older people in the People's Republic of China. Int J Geriatr Psychiatry. 1999 Oct;14(10):821-30.

48 Zhou X, Bi B, Zheng L, Li Z, Yang H, Song H, et al. The prevalence and risk factors for depression symptoms in a rural Chinese sample population. PLoS One. 2014 Jun;9(6):e99692. 